IZA DP No. 8081

Production Risk, Energy Use Efficiency and Productivity of Korean Industries

Nabaz T. Khayyat

Almas Heshmati

March 2014 


\title{
Production Risk, Energy Use Efficiency and Productivity of Korean Industries
}

\author{
Nabaz T. Khayyat \\ TEMEP, Seoul National University \\ Almas Heshmati \\ Sogang University \\ and IZA
}
Discussion Paper No. 8081
March 2014

\author{
IZA \\ P.O. Box 7240 \\ 53072 Bonn \\ Germany \\ Phone: +49-228-3894-0 \\ Fax: +49-228-3894-180 \\ E-mail: iza@iza.org
}

Any opinions expressed here are those of the author(s) and not those of IZA. Research published in this series may include views on policy, but the institute itself takes no institutional policy positions. The IZA research network is committed to the IZA Guiding Principles of Research Integrity.

The Institute for the Study of Labor (IZA) in Bonn is a local and virtual international research center and a place of communication between science, politics and business. IZA is an independent nonprofit organization supported by Deutsche Post Foundation. The center is associated with the University of Bonn and offers a stimulating research environment through its international network, workshops and conferences, data service, project support, research visits and doctoral program. IZA engages in (i) original and internationally competitive research in all fields of labor economics, (ii) development of policy concepts, and (iii) dissemination of research results and concepts to the interested public.

IZA Discussion Papers often represent preliminary work and are circulated to encourage discussion. Citation of such a paper should account for its provisional character. A revised version may be available directly from the author. 


\section{ABSTRACT \\ Production Risk, Energy Use Efficiency and Productivity of Korean Industries}

Korea imports all of its primary energy, which leads to high dependency and vulnerability related to its energy supply. Efficiency in the use of energy is a way to reduce dependency and emissions. This study provides empirical results of the stochastic production process in energy use. Special attention is given to the factors that increase the risk or variation of using more of the energy input in production. A dynamic panel model is specified and applied to 25 Korean industrial sectors over the period 1970-2007. The determinants of energy use are identified and their effects in the form of elasticities of energy use are estimated. Stochastic production technology is applied to estimate an energy demand model based on an inverted factor demand. The findings reveal that: first, there are large variations in the degree of overuse or inefficiency in energy use among the individual industries as well as over time; second, information and communication technology (ICT) capital and labor are substituting for energy; and third, ICT capital input decreases the variability of energy demand while nonICT capital, material and labor increase the variability of energy demand. The results suggest that technical progress contributes more to the increase in the mean energy demand than to the reduction in the level of risk. It is recommended that industries increase their level of ICT capital as well as digitalize and invest more in R\&D activities and value added services to reduce the uncertainty related to their demand for energy.

JEL Classification: C23, D24, L60, O13, O33

Keywords: production risk, energy use efficiency, technical change, stochastic production, panel data, industrial sector, Korea

Corresponding author:

Nabaz T. Khayyat

Technology Management, Economics, and Policy Program

College of Engineering

Seoul National University

San 56-1, Sillim-Dong, Kwanak-gu

Seoul 151-742

South Korea

E-mail:nabaz@snu.ac.kr 


\section{Introduction}

The overall consumption of energy worldwide is continuously increasing. According to the international energy outlook report published in 2011 by the USA Energy Information Administration (EIA), energy consumption will increase by 53\% worldwide by the year 2035 . To put this in perspective, the total worldwide energy consumption in 2008 was 505 quadrillion BTUs (British thermal unit), with the expectation that it will reach 770 BTUs by the year 2035 (EIA, 2011). This steady increase in the energy demand will negatively affect the environment, as well as the sufficiency in the availability of depletable energy sources of fuel and/or primary energy needed to produce most of the energy output, such as electricity.

Strong economic development leads to an increase in the demand for energy in the industrial sector, which consumes at least $37 \%$ of the total energy supply. This sector is relatively more energy intensive than any of the other major sectors, including household, agriculture and public services (Abdelaziz et al., 2011; Friedemann et al., 2010). A recent study conducted by the USA Environmental Protection Agency (EPA) in 2007 revealed that 30\% of the energy consumed by industrial and commercial premises is wasted due to inefficient use and a lack of risk management tools (EPA, 2007).

Energy use efficiency is an important issue, due to limitations in the possibility of replacement energy as a substitutable input factor in production processes. The efficient use of energy may reduce the amount of fuel or primary energy needed to produce energy output such as electricity. This will reduce the energy use intensity, which is expected to contribute to a reduction in the corresponding global emissions of air pollution and greenhouse gases (EIA, 2011).

A key variable of interest in a study of efficiency and productivity in the industrial sector is the energy demand. It can be considered a significant variable in the cost structure of any industry and an essential determinant of the level of energy demand by these other industries (Allan et al., 2007; Mukherjee, 2008). Energy is an important factor of production in many industries, as it is considered an important source of economic growth and effectiveness in production. Energy use efficiency has continuously improved following the increased implementation of higher quality technology in production, as well as in response to the increase in fuel prices (Soytas and Sari, 2009; Stern, 2011). The energy sector is undergoing reforms toward using more advanced technology in the generation, transmission and distribution stages (Fukao et al., 2009). The aim is to increase energy efficiency by reducing the cost of generation and waste in the transmission and distribution stages of energy (here referring mainly to electricity).

Unlike normal goods where a supply response is used to meet increased demand, in the case of the energy market, a demand response is employed to reduce the increased demand. For example, the use of smart grid technology as part of a demand response program allows for the application of price variation/discrimination by the type of consumer, location, season and hours of the day with the aim of reducing energy consumption. It improves the producer's and consumer's ability to optimize the generation and consumption of energy. Better optimization improves energy use and efficiency, which will also reduce the energy generated at the peak time reserve capacity at a high cost and energy consumption during the peak time at a high price (Heshmati, 2014).

This empirical study investigates the impact of different input factors of production and market, consumer and producer characteristics on the energy demand in the industrial sector for South Korea during the period 1970-2007. In this study, the energy demand is based on a derived factor 
demand model (Hicks, 1961; Urga and Walters, 2003), where the industry's objective is to minimize the use of energy to produce a given level of output. The aim is to formulate an energy demand structure for the South Korean industrial sector as a tool to enable producers and policy makers to evaluate different alternatives towards reducing energy consumption, as well as using energy in a more efficient way.

Following the estimation of the inverted factor demand model, the Korean industry-wide level of energy efficiency ratio is estimated using a panel data model. Efficiency is estimated relative to the best industry sector technology in a given year. The model includes the estimation of production risk or, in other words, variation in energy use. The energy demand model is estimated by accounting for risk or variation in demand using a translog function. Since the translog model is non-linear in the model specification (Berndt and Wood, 1975; Christensen et al., 1973; Griffin and Gregory, 1976), it allows for inference on substitution and complementary relationships between factors of production.

Following this introductory section, a literature review is provided in Section 2. Section 3 covers the theoretical framework. The data source, model estimation, parameter estimates and their interpretations are provided in Section 4. Section 5 concludes.

\section{Review of Literature}

\subsection{The Theory of Firm Behavior under Production Risk}

Studies on producers' behavior under risk and uncertainty emphasize that producers often make their decisions in a risky environment that result from production (Arrow, 1971; Pratt, 1964; Robison and P., 1987; Sandmo, 1971; Tveteras et al., 2011). Such risky production environments and conditions may be related to different factors that also vary according to the production type and the input factors used in production. For example, in the industrial sector, the market for and price of energy used as an input factor, as well as financial uncertainty, such as in the interest rate, may have significant impacts on the producer's decision and production outcome. In the agricultural sector, this uncertainty may arise from the weather, disease and pests.

In general, producers try to minimize risk through different institutional and managerial tools (Binswanger, 1980). For example, they may change the level of different inputs used for optimal production. Empirical studies show that risk averse producers tend to optimally use inputs with less risk during uncertain situations than they would under certainty (Hurd, 1994). These inputs might be used to either increase the level of output or reduce the variability in the output, and thus any possible changes in their level of utilization might have different implications regarding the variability in the output. Output risk can be present in many different productions and industries, such as the agriculture, mining, medical and health, sectors. However, the level of output risk may differ for production types, industries and location, as well as over time (Tveteras et al., 2011).

The distributional properties for output in the case of output risk have implications for optimum input combinations and output for risk averse producers. When the level of inputs is changed, a consequence is that the variance of output will be changed in addition to the mean of output. For risk averse producers, the optimal level of inputs will be higher if an increase in the level of inputs leads only to a higher expected output, rather than if the increase leads to a higher mean and larger variance of output (Tveterås, 2000; Tveterås and Heshmati, 2002). From this 
perspective, different econometric methodologies have been used to analyze the production process, and different assumptions have been imposed in ways that have prevented researchers from further investigating the effects of input factors on the variability of output (Fufa and Hassan, 2003). As a consequence, many researchers have proposed different models that allow one to analyze the effects of production risk on the level of inputs, such as the well-known Just and Pope production function (Just and Pope, 1978) model. Here, Just and Pope propose a generalized stochastic production model that consists of two general deterministic parts, one to specify the impact of input factors on the mean of output and the other to specify the impact on its variance. The latter of which allows for input factors to be risk increasing or decreasing (Koundouri and Nauges, 2005; Koundouri et al., 2006). Just and Pope (1978) offer eight important propositions for the stochastic specification of the production function (or input-output relationship). According to their argument, these propositions are important on the basis of a priori theorizing and observed behavior. The propositions are stated in Appendix A.

\subsection{Production under Uncertainty}

According to Kumbhakar and Tsionas (2010), there are two main aspects of the concept of risk in production theory that have been studied. First, uncertainty arises from the change in the price of output, and second, uncertainty arises from the volume of output. The latter is often referred to as the production risk that can be explained by the inputs used in production. The quantity of inputs that determine the output volume also influences the degree of output inconsistency or variability. For example, in the financial and agricultural sectors respectively, interest rates and the use of fertilizers and pesticides may be risky, leading to an increase in the variation of the output, while technology and labor may decrease the output risk. Other risks may increase or decrease the output. For example, currency risk in the financial sector, which is related to changes in the rate of foreign exchange, will have positive/negative effects on the value of the asset held in that currency (Asche and Tveteras, 1999; Kumbhakar et al., 2002; Kumbhakar and Tveterås, 2003).

Literature on production risks is mainly analyzed theoretically, and consequently only a few empirical studies exist (Coppejans et al., 2007; Kumbhakar, 2002a). The empirical studies have been based on either output price uncertainty or the Just and Pope (1978) production risk framework, where the main focus has been on how changes in the level of inputs affect variation in the range of output. An empirical study by Appelbaum and Ullah (1997) on the firm's production decision behavior analyzes the supply and demand decision under price uncertainty using data on two industries, one being printing and publishing and the other in stone, clay, and glass, from the USA and finds that uncertainty has a highly statistically significant effect on production decisions.

Kumbhakar (2002b) jointly estimates the production technology and risk preference functions represented by variable input choice equations under output price uncertainty. He applies the model to panel data of 28 Norwegian salmon farms for the period 1985-1992. He finds that the absolute risk aversion in the salmon farms is decreasing and all salmon farms are risk averse. Tveterås (1999), based on the Just and Pope (1978) production risk, estimates production risk using an unbalanced panel data model of Norwegian salmon farms focusing mainly on the measurement of the properties of risks related to input factors and productivity growth. He finds that input factors of production can be used as instruments for controlling risk. Another finding is 
that heterogeneity in the production, using the same input factors of production, yield different levels of output risk. Tveterås (2000) estimates flexible panel data models for risky production technologies by applying Just and Pope (1978) production risk and using an unbalanced panel data of Norwegian salmon farms. He shows that the empirical results are, to a large extent, influenced by different specifications of unobservable firm-specific effects as well as different functional forms underlying the production and risk specifications. In another study relying on the Just and Pope (1978) propositions, Tveteras et al. (2011) estimate the mean and variance functions of production risk separately in the presence of heteroskedasticity using a two-step procedure and second order approximation. They find that the structure of the production risk has implications in production decisions for the risk averse producers.

As depicted by Fufa and Hassan (2003), firms that account for risk involved in the input factors used in production need to measure the factors that affect the distribution of return, which is the variance rather than the mean of inputs. For producers and policy makers in managing risk, it is essential to know which input factor increases (decreases) the risk of the production output. Kumbhakar and Tsionas (2010), through explaining how the input factors affect risk related to factor demand, find that input factors of production influence the probability distribution of output, and thus have an important meaning for the decision makers.

Tveterås (2000) claims that the deterministic setting approach is applied by many scholars in the econometric productivity studies. This approach estimates either the basic production model or the dual translog production model, which, according to Coyle (1999), is considered to be less tractable under risky production when compared with the conventional deterministic setting. The marginal risk of input A tends to be positive (negative) if the increase (decrease) in the variance of the output is a result of the increase in the level of input A. Just and Pope (1978) found that the marginal risk and the inputs/output relationships cannot be explained precisely using the deterministic settings. Instead, they develop a risky production function version that allows for input factors to affect the mean and variance of the production output. The error component of their proposed function is modeled with an input dependent heteroskedastic form. Thus, the model, in addition to accounting for risk, also accounts for heteroskedasticity.

Many scholars who have applied the Just and Pope (1978) methodology have implied that production risks have failed to address two main issues. First, for simplicity the basic CobbDouglas production function is used in both the deterministic part and the variance part despite its weakness, which imposes a strong restriction on the production technology. However, using the translog model, which is more flexible than the basic Cobb-Douglas function, is more favorable in spite of its requirement to use a non-linear estimation method. The choice of a generalized functional form, such as the translog, compared with a simpler form is statistically testable. Second, variations in capital and different input factors based on specific producer characteristics, in regard to producer heterogeneity, matter, which has been neglected by researchers who have applied the Just and Pope Production function.

In the case of this study, the same idea is applied, but in the context of energy demand. Here the meaning of risk is not the same as in the risk in production. An increase in price is a negative shock or risk, and technical progress in the area of energy savings is a positive shock. ICT capital is another factor that might serve as either a positive or negative shock to energy demand. All these factors increase the changes or variability in energy demand. The methodology in this study, as is similar to the production risk approach, deals with heteroskedasticity of a known 
form. It is to be considered an attempt to identify and estimate the effects of the determinants of variation in production and energy demand.

\section{Theoretical Framework and Estimation Procedure}

\subsection{Model Specification}

Let $Y_{i t}$ be the amount of output which can be produced by industry $i$ at time $t$. Production of $Y_{i t}$ will use different combinations of ICT-capital (I), non-ICT capital $(K)$, labor $(L)$, material $(M)$, services $(S)$, and energy $(E)$. In addition to that, exogenous technical changes represented by a time trend $T$ will have an impact on production (Heshmati, 2003). The production function is specified as follows:

$$
Y_{i t}=F\left(K_{i t}, L_{i t}, M_{i t}, S_{i t}, I_{i t}, E_{i t}, T_{i t}\right)
$$

Based on Diewert (1974) and using Shephard’s lemma (Shephard, 1953), the demand for energy can be written as an inverted factor demand:

$$
E n_{i t}=f\left(Y_{i t}, P_{i t}, K_{i t}, L_{i t}, M_{i t}, S_{i t}, I_{i t}, T_{i t}\right)
$$

The price of energy $P$ is included due to the cost minimization requirement. This factor demand function for energy depends on output, the own price, other inputs, and a time trend representing the technology.

The general form of the Just and Pope (1978) production technology can be expressed as follows:

$$
y=f(x)+u=f(x)+g(x)^{1 / 2} \varepsilon
$$

where $x$ is a vector of $m$ inputs, $f(x)$ is the explained (deterministic)/mean function part, $g(x)$ is the risk (variance function) part, and $\varepsilon$ is an exogenous random shock beyond the control of the producers.

According to the specification in equation (3), the input vector $x$ affects both the mean (output) and the variance part (output risk) independently. Equation (4) provides an illustration of this relation:

$$
E(y)=f(x), \text { and } \operatorname{Var}(y)=\operatorname{Var}(u)=g(x) \sigma_{\varepsilon}^{2}
$$

In addition, there is no restriction on the risk effects of inputs, i.e. $\frac{\delta v a r(y)}{\delta x_{k}}=g(x)$ can be either positive, negative or zero. Although this is a strong assumption imposed by the Just and Pope production function, it allows the model to be less restrictive and more realistic.

As should be noted from equation (3), the explained component (deterministic part) will interact multiplicatively with the unexplained component (variance part). Furthermore, the error term is not specified in a familiar multiplicative form, such as $y=f(x) e^{u}$, but it is rather an additive form, such as $y=f(x)+u$. For this reason, the Just and Pope production technology model needs to be nonlinearly estimated.

A flexible translog functional form can be used to represent the energy demand function when the demand for energy is a function of the energy price, industrial production activities, other inputs, and industry and time specific effects. The variance function appears multiplicatively 
with the demand function, and it accommodates both positive and negative marginal effects of the determinants of energy demand, as well as its effect on the energy use pattern. Unlike in traditional models with heteroskedasticity in and unknown form, the variance function allows the energy demand model to be heteroskedastic with a specified form. It is specified to be a function of the production input factors as well as with energy policy and environmental variables.

\subsection{Estimation Procedure}

\subsubsection{A Two-Stage Estimation Procedure for the Variance Function Parameters}

A two-stage estimation procedure exists for the Just and Pope production function. It relies on the use of a consistent estimator of the variance function parameters vector $\beta$ in the first stage. The least square estimate of $\beta$ is consistent, and it can be used in the first stage. In the second stage, $\beta$ is estimated relying on the following specification described in Harvey (1976):

$$
\widehat{\boldsymbol{\beta}}_{(2)}=\widehat{\boldsymbol{\beta}}_{(1)}+\Phi+0.2804\left[\sum_{i=1}^{n} \dot{z}_{l} z_{i}\right]^{-1} \sum_{i=1}^{n} \dot{z}_{l} e^{-z_{i} \widehat{\beta}_{(1)} \widehat{u}^{2} i}
$$

where $\hat{\beta}_{(1)}$ is the first stage (estimated by least square) estimate of the $m \times 1$ parameter vector $\beta$, $z_{i}$ is the $1 \times m$ vector of regressors (with the first element one), $\Phi$ is an $m \times 1$ vector in which the first element is $(0.2704)$ and the remaining elements are zero. The second stage estimate $\hat{\beta}_{(2)}$ is considered asymptotically efficient (Tveterås, 1997).

\subsubsection{The Energy Demand Model with Production Risk}

Let the energy demand function of the South Korean industrial sector be specified as follows:

$$
\boldsymbol{E n}_{\boldsymbol{i t}}=\boldsymbol{f}\left(\boldsymbol{y}_{i t}, \boldsymbol{p}_{i t}, \boldsymbol{q}_{i t}, \boldsymbol{t}_{i t}\right) \boldsymbol{e}^{\varepsilon}, \varepsilon=\mu_{i t}+\mathrm{v}
$$

where $E n$ is the energy demand, $f$ represents the functional form of the energy consumption technology, $y$ is the value added which is produced by using energy, $p$ is the price of energy, $q$ is a vector of factor inputs of production and $t$ represents the energy consumption technology. The relationship specified in equation (6) defines the energy consumption possibility frontier given the level of output as depicted by Diewert (1974). The model can be viewed as the energy input requirement function.

An industrial sector may use energy in excess of what is technically necessary to produce a given level of output. Therefore, its demand for energy depends on the following: (i) the functional form of the energy consumption technology $f$, (ii) energy use inefficiency $\mu$ and (iii) random factors outside the control of the industries $v$, such as different types of unanticipated policies and external shocks which impact the industry.

According to Aigner et al. (1977), the value of $\mu>=0$ is interpreted as an energy use inefficiency, or the overuse of energy in this case. It represents the percentage of energy consumption in excess of the minimum amount of energy required to produce a given level of output. If $\mu=0$ for an industry, it is said to be fully efficient in the use of energy. Since random factors can be both favorable $(v<0)$ and unfavorable $(v>0)$, the error term $v$ can take both positive and negative values, i.e. $-\infty<v<\infty$. The energy demand frontier is obtained by setting $\mu$ $=0$. The energy demand frontier is, therefore, stochastic because of the presence of $v$. In 
similarity with the commonly known stochastic frontier model, the demand model here is a stochastic energy demand model.

The energy demand function can be generalized to incorporate risk according to Just and Pope (1978) and interpreted as an energy demand frontier written as:

$$
\boldsymbol{E n}=\boldsymbol{f}(\boldsymbol{x} ; \boldsymbol{\alpha}) \boldsymbol{e}^{\boldsymbol{g ( x ; \boldsymbol { \beta } )} \varepsilon}
$$

where $x=(y, p, q, t), f(x ; \alpha)$ is the deterministic part, $g(x ; \beta) \varepsilon$ is the variance part and can be modeled with a known form heteroskedasticity, and $x$ is the prime determinant of the variance of energy use. Taking the logarithm of equation (7), the factor demand model, its mean, and its variance can be written in the following linear form:

$$
\begin{aligned}
& \ln (E n)=\ln (f(x ; \alpha))+g(x ; \beta)+\varepsilon \\
& E(E n)=f(x ; \alpha) e^{\frac{g^{2}}{2}} \\
& V(E n)=f^{2} e^{g^{2}}\left(e^{\frac{g^{2}}{2}}-1\right)
\end{aligned}
$$

If the expected value of $E$ results in $E(E n) \geq f(x ; \alpha)$, the marginal effect (marginal variance), $M E$, with respect to input $j$ is:

$$
\left.M E_{j}=\frac{\partial V(E n)}{\partial x_{j}}=2 \cdot f \cdot e^{\frac{g^{2}}{2}} \cdot\left[f_{j} e^{g^{2}}-1\right)\right]+f \cdot g \cdot g_{j} \cdot\left(2 e^{g^{2}}-1\right)
$$

The rate of technical change from period $s$ to period $t$ can be specified assuming a translog specification as follows:

$$
\boldsymbol{T} \boldsymbol{C}_{\boldsymbol{s}, \boldsymbol{t}}=\left(\boldsymbol{\theta}_{\boldsymbol{t}}-\boldsymbol{\theta}_{\boldsymbol{s}}\right)+\sum_{j}\left(\boldsymbol{\theta}_{\boldsymbol{j}, \boldsymbol{t}}-\boldsymbol{\theta}_{\boldsymbol{j}, \boldsymbol{s}}\right) \ln \left(\boldsymbol{x}_{\boldsymbol{j}}\right)
$$

where the term $\left(\theta_{t}-\theta_{s}\right)$ is the pure component that is only time dependent and the summation term is the non-neutral component which depends on the level of input utilization.

In a production case, the elasticity of output with respect to input $j$ is specified as follows:

$$
\boldsymbol{E} \boldsymbol{l}_{j}=\frac{\delta y}{\delta x_{j}} \cdot \frac{x_{j}}{y}=\frac{\delta \ln y}{\delta \ln x}=\beta_{j}+\sum_{k} \beta C_{k j} \ln x_{k}+\beta C_{j t}
$$

The subscripts $i$ and $t$ representing the industry and time periods, respectively, are neglected for simplicity. The vector of parameters $\beta$ is the estimated coefficients of the production model.

We do not impose constant returns to scale, and the rate of returns to scale (RTS) is the sum of $j$ output elasticities in a production function case. The RTS can be calculated as the sum of the input elasticities as follows:

$$
R T S=\sum_{j}\left(E l_{j}(x)\right)=\sum_{j} \frac{\partial f}{\partial x_{j}} \cdot \frac{x_{j}}{f(x)}
$$

For the energy demand model, RTS is obtained by the inverse of the derivative of energy demand with respect to changes in the output. It represents the returns to scale corresponding to the one explained above in the case of a production function.

Using a translog functional form to approximate $f$ in equation (8), the following relation can be obtained: 


$$
\ln E n_{i t}=\alpha_{0}+\sum_{i} \alpha_{i} \ln y_{i t}+\alpha_{p} \ln p_{i t}+\alpha_{q} \ln q_{i t}+\frac{1}{2}\left\{\sum_{i} \sum_{k} \alpha_{i k} \ln y_{k t}+\alpha_{p p} \ln p_{i t}^{2}+\right.
$$

$\left.\alpha_{q q} \ln q_{i t}^{2}\right\}+\sum_{i} \alpha_{i p} \ln y_{i t} \ln p_{i t}+\sum_{i} \alpha_{i q} \ln y_{i t} \ln q_{i t}+\alpha_{p q} \ln p_{i t} \ln q_{i t}+\left\{\sum_{i} \beta_{i} y_{i t}+\beta_{p} p_{i t}+\right.$ $\left.\beta_{q} q_{i t}+\beta_{t} t\right\} \times\left[\mu_{i}+v_{i t}\right]$

Following the same steps outlined in Heshmati (2001) that used this model in the context of labor demand, the estimation steps are described as follows:

Step 1: Ignore the variance function $\mathrm{g}(\mathrm{x} ; \beta)$ and estimate equation (15) by OLS or least squares dummy variable (LSDV) methods, where $\mu_{\mathrm{i}}$ is estimated from $n-1$ industry dummies. The error term which contains the variance function parameter will be heteroskedastic of an unspecified form (Caudill et al., 1995; Kumbhakar, 1997).

Step 2: From estimating $\alpha$, and $\mu$ in step 1 , the residual, $e$, can be obtained as follows:

$$
\begin{aligned}
& \quad e_{i t}= \\
& \ln E n_{i t}-\left\{\alpha+\sum_{i} \alpha_{i} \ln y_{i t}+\alpha_{p} \ln p_{i t}+\alpha_{q} \ln q_{i t}+\frac{1}{2}\left[\sum_{j} \sum_{k} \alpha_{j k} \ln y_{j i t} \ln y_{k i t}+\alpha_{p p} \ln p_{i t}^{2}+\right.\right. \\
& \left.\left.\alpha_{q q} \ln q_{i t}^{2}\right]+\sum_{j} \alpha_{j p} \ln y_{j i t} \ln p_{i t}+\sum_{j} \alpha_{j q} \ln y_{j i t} \ln q_{i t}+\sum_{j} \alpha_{p q} \ln p_{i t} \ln q_{i t}+\mu_{i}\right\}
\end{aligned}
$$

The values of the estimate's residual will be used to estimate the variance function by the nonlinear estimation method as follows:

$$
\ln \left(e_{i t}\right)=-1.2704+\ln \left\{\sum_{j} \beta_{j} y_{j i t}+\beta_{p} p_{i t}+\beta_{q} q_{i t}+\beta_{t} t\right\}+\ln v_{i t}
$$

It should be noted that the energy demand is specified as a flexible translog functional form, while the variance function is simple without any interaction or square terms. The error term converges to $v_{i t}$, which is Chi-square with one degree of freedom. Therefore, according to theorem 2 in Just and Pope (1978), the mean and variance of $I n v_{i t}$ are (-1.2704) and (4.9348) respectively (Griffiths and Anderson, 1982).

Step 3: The models in equations (15) and (17) together form a non-linear model and therefore must be estimated in an iterative procedure accounting for heteroskedasticity using a Feasible Generalized Least Square (FGLS) estimator (Greene, 2008; Wansbeek and Kapteyn, 1989) in order to obtain efficient estimates of $\alpha$ and $\beta$. FGLS is more efficient than simple least squares dummy variable estimates of the model. Since the model is non-linear, an iterative procedure is used. Convergence will be obtained after a repeated iteration process, which is equivalent to using a maximum likelihood estimation method (Greene, 2008).

The marginal risk (variance) effect for $g($.$) , which is analogous to the demand elasticity based on$ $f($.), is calculated. A variable is variance increasing if $M E>0$, and variance decreasing if $M E<0$. The total marginal effect (sum of individual MEs) is analogous to the scale effect in energy consumption derived from $f($.). If the total marginal effect is greater than zero, i.e $M E>0$, then an expansion of output level leads to an increase in the energy demand variance. The variance and $M E$ can be used as policy variables (Battese et al., 2000) to help identify which factors increase or decrease the variance of energy demand. 


\subsection{Data Source}

The data used in this study is obtained from the harmonized EU KLEMS growth and productivity account database (November 2009 release). The database is publicly available at http://www.euklems.net. Details of the data and construction of the variables, along with the industries' characteristics, are provided in Appendix B.

\section{Empirical Results and Discussion}

\subsection{Parameter Estimates}

The parameter estimates for the energy demand (not accounting for risk) are reported in Appendix Table C.1. The parameter estimates of the energy demand accounting for risk are reported in Appendix Table C.2. In the second stage, the variance function is estimated by nonlinear least squares. Using the estimated variance, the model is re-estimated based on transformed data in the third step. In the third stage, the translog function $f(x)$ is estimated by least squares with predicted variances from the second step as weights. These parameter estimates are reported in Appendix Table C.3. The error term $\mu_{i}$, from the estimated coefficients in equation (6), is treated as an industry fixed effect and is estimated based on the input variables and industry specific characteristics, such as the technology level, size, R\&D scale, etc.

The FGLS estimator for the Just and Pope production risk with fixed industry specific intercepts will be the same as the usual FGLS estimator when the fixed effects are implemented as dummy variables (Tveterås, 2000). Furthermore, technical inefficiency in industry $i$ is estimated relative to the industry with the best performance (in terms of using least energy per unit of output) in the sample. Recall that an industry is assumed to be fully efficient if $\mu_{i}=0$. However, the reference industry may not be the best in all the years, therefore we allow technical inefficiency to be timevarying and we measure it relative to the industry with the best performance in each given year. The procedure is similar to those applied in Heshmati (2001) and Lovell and Schmidt (1987):

$$
\begin{aligned}
& \text { TINEFF } i t=g\left(x_{i t} ; \beta\right)\left(\alpha_{0}+\mu_{i}\right)-\min _{t}\left[g\left(x_{i t} ; \beta\right)\left(\alpha_{0}+\mu_{i}\right\}\right] \\
& \text { TEFF }_{i t}=\exp \left(- \text { TINEFF }_{i t}\right)
\end{aligned}
$$

where TINEFF and TEFF refer to technical inefficiency and technical efficiency, respectively.

If the marginal variance of input $j: M E_{j}$ specified in equation (11) is positive, then the input $j$ is said to be risk increasing, while it is said to be risk decreasing if the sign is negative. The estimated variance from equation (10) is an increasing function of the expected mean of energy demand. The total variance is then divided into two components: output variance and input variance (Heshmati, 2001).

\subsection{Econometric Tests of the Model}

The model's coefficient of determination $\left(\mathrm{R}^{2}\right)$ is equal to 0.924 , implying that more than $92 \%$ of the variation in the data can be explained using this model. Most of the parameters are highly statistically significant. The regularity conditions in this model are also tested, requiring both monotonicity and concavity. The concavity can be tested by examining the matrix of the 
elasticities of inputs and output specified in equation (13) for semi-definite negativity, as explained by Gallant (2008). The frequencies of positive marginal productivities of the estimated translog energy demand function with risk are as follows (see Appendix Table C.4, column 4): output 0.739 , non-ICT capital 0.863 , labor 0.268 , material 0.497 , services 0.764 and ICT capital 0.138 . These frequencies indicate that the average positivity of the logarithmic marginal products with respect to output and each input factor of demand are satisfied.

The convexity of own price elasticity is also satisfied, with (0.928) indicating that more than $92 \%$ of the data points satisfy the convexity condition of own price elasticity in the energy demand model with risk. The curvature conditions in the energy demand model with risk are also tested and show that the eigenvalues of the elasticities are mixed in sign. The sample average elasticities for price, output, capital, labor, material, services, ICT capital and time trend are $1.178,0.805,0.195,0.008,-0.066,-0.300,-1.122$ and -2.564 , respectively. The negative sum of 1.866 indicates a negative semi-definite value, confirming that the second regularity condition is also satisfied (Moss et al., 2003).

A Harvey-specification test (Harvey, 1976), based on the FGLS estimator, is undertaken for the pooled energy demand model with risk. The null hypothesis states that all coefficients of the multiplicative variance function, except the intercept $\beta_{0}$, are zero. The Harvey test statistic is RSS/4.9348, where RSS is the residual sum of squares of the estimated variance function, and is asymptotically distributed as chi-square with the degrees of freedom equal to the number of regressors. In our model, the Harvey test statistic for the variance function $\log (e)$ is (944.982) with 25 degrees of freedom. This is noticeably higher than the chi-squared value of 46.928 at the $99 \%$ level of significance. Thus the null hypothesis is rejected and the model with the variance function is accepted.

\subsection{Returns to Scale}

The RTS for the energy demand model is 2.938, indicating that, on average, increasing returns to scale are present. This shows an increase in output resulting from increased energy use, conditional on other inputs and technology. In Figure 1, where industries are distributed based on their returns to scale, it is shown that all industries exhibit increasing returns to scale, except for the agriculture, hunting, forestry and fishing (industry code 1) and post and telecommunication (industry code 23) industries. This implies that these industries are energy dependent for their given level of production. 


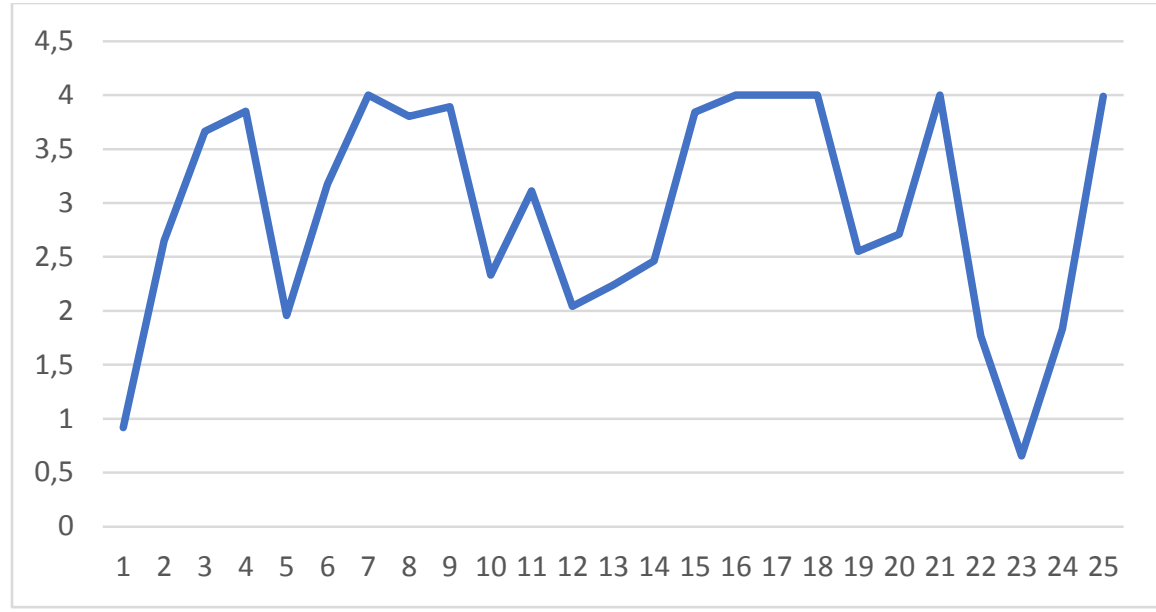

Figure 1. Rate of Returns to Scale by Industry

\subsection{Elasticities}

Several important conclusions can be drawn from the reported results in Appendix Tables C.4, and C.6-C.8. First, the own price elasticity of energy (the mean energy demand elasticity with respect to energy price) is -0.591 with a standard deviation of 0.532 , which implies an expected negative responsiveness of the energy demand with a change in the energy price. Second, the elasticity of demand for energy use with respect to its price rate is the largest in the mining and quarrying sector (industry code 2) with a value of -1.247 . This is followed by financial intermediation sector (industry code 20) with value of -1.121 , the public administration and defense sector (industry code 22) with value of -1.115 , the real estate, renting ad business activities sector (industry code 21) with value of -1.091 , the whole sale and retail trade sector (industry code 16) with value of -1.041 , and the agriculture forestry, hunting and fisheries sector (industry code 1) with value of -1.024 . These figures indicate a highly elastic energy demand with respect to its price. The industries are generally less energy intensive and relatively more dependent on energy than other sectors. On the other hand, the industries that are less responsive to changes in energy price are the transport equipment sector (industry code 12) with value of 0.309 , the machinery, NEC sector (industry code 10 ) with value of -0.349 , the textile, leather and footwear sector (industry code 4 ) with value of -0.368 , the pulp, paper, printing and publishing sector (industry code 6) with value of -0.373 , and the hotels and restaurants service sector (industry code 17) with value of -0.393 .. There are different reasons for such behavior in the energy price elasticity. For example, the transport equipment sector (industry code 12) and the machinery, NEC sector (industry code 10) are the two industries with the most intensive use of energy, implying that energy use is an essential factor of production. Therefore, they are less likely to be responsive to changes in the energy price. The other three industries that exhibit smaller elasticities are classified as low tech industries, and they are unable to substitute the energy input with other factors of production that have a lower price.

Third, disparities are found between the elasticities of energy with respect to capital, materials and services. The mean elasticities of energy with respect to capital and materials are 0.175 and 0.068, respectively, indicating slight differences in the responsiveness between energy with capital and energy with materials. The elasticity of energy with respect to capital is interpreted as, a $10 \%$ increase in capital leads to $1.75 \%$ increase in energy use. A larger response can be 
found between energy with services, as indicated by a mean elasticity of 0.349 . The non-ICT capital elasticity over time is positive, however, it continuously decreases. The highest and lowest non-ICT capital input elasticities are found in the wood and cork sector and basic metals and fabricated metal sector, corresponding to 0.479 and 0.075 , respectively. Since the financial crisis, elasticities have been declining towards zero, although the level varies greatly over time.

Fourth, energy is found to be have been substituted by ICT capital and labor with mean elasticities of -0.175 and -0.172 , respectively. That is, a $10 \%$ increase in labor decreases energy use by only $1.72 \%$. Over time, all of the elasticities are negative. This implies that labor provides an opportunity to substitute for the energy input, but that employment is not an important factor in energy use. Across industries, the labor elasticities are both positive and negative. The elasticities vary between -0.972 for the education sector (industry code 23) and 0.638 for the wood and cork sector (industry code 5). This result shows that it is not sufficient to focus on the substitution of labor inputs for energy, but that one has to look at the dispersion across industries and over time. The effects of ICT capital on energy use, as mentioned above, show that a $10 \%$ increase in investment of ICT will yield a 1.75\% decrease in use of energy. Therefore, a similar effect exists between ICT capital with energy and labor with energy.

Fifth, the mean energy demand elasticity with respect to output is 0.499 . This is interpreted as energy use increasing by roughly $0.5 \%$ for every $1 \%$ increase in output, holding all else constant. The sign of the elasticity is positive as expected, suggesting that more energy is required to increase output. An output elasticity of energy that is less than 1.0 suggests that economic growth leads to higher energy use, but with increased efficiency. Although economic growth can be helpful to the productivity per unit of energy used, it makes total energy use and $\mathrm{CO}_{2}$ emissions increase. Thus a paradox exists between increasing efficiency and reducing emissions (IEA, 2011). Industry-wise, the output elasticities vary between 1.222 for the agriculture, hunting forestry and fishing sector and 0.251 for the other community, social and personal services sector. Over time, there is large variation in the elasticities, which can be depicted by a Wshaped curve. Variation is present across industries as well, reflecting differences in energy use efficiency and saving rates across different industries.

Over time, no systematic pattern is observed in the development of energy price elasticity. All mean elasticities of the energy price in each year are as expected negative. The energy demand responsiveness for a change in its own price has declined dramatically over time, although the fluctuations in the period from 1988 to 1996 occur due to the effects from the second oil supply shock. This indicates that the relationship between economic growth and energy demand becomes more feasible after industrialization (Kamerschen and Porter, 2004).

The rapid development of the production capacity in the Korean industries over time have led to an expansion in these industries and the urbanization process, as well as an increase in the national economy (Lee et al., 2012). As a result, the response to a change in the energy price has little effect on the total demand for energy over time. The process of industrialization in South Korea has transformed its economy from an agriculturally dominated structure into a service based one, with an annual GDP growth of $2.9 \%$ (Cho et al., 2004). High growth rates of $4-5 \%$ have been observed during the four decades of industrialization. Hence, the increase in GDP per capita has led to a significant increase in the energy demand. A possible explanation may be the shift away from labor intensive industries to more capital and energy intensive ones. Additionally, the urbanization process resulting from industrialization has led to a greater demand for energy due to the expansion in services, food delivery, development and the 
maintenance of infrastructure (Liu, 2009), as the energy demand model will be further specified accounting for risk.

\subsection{Marginal Effects}

The marginal effects (marginal variances) with respect to input $\mathrm{j}$, as in equation (11), are calculated for each input. The figures are equivalent to the total elasticity of energy with respect to output and each input. The total marginal effects are also calculated by summing up the individual marginal variances, which is equivalent to the returns to scale discussed previously. If the total marginal effects are positive (negative) then expanding in the level of output will lead to an increase (decrease) in the energy demand variance (Heshmati, 2001). The variance is considered to be an increasing function of the expected value of the mean of the energy demand. The estimated parameters are reported in Appendix Table C.5.

The empirical model of the energy demand with risk provides evidence of significant marginal effects in inputs, which indicate that some inputs are risk increasing and some are risk decreasing. In other words, since the input risk is a function of inputs and industries' characteristics, the input level then can be used as an instrument to control the level of risk. Services and ICT capital are the only two inputs that decrease risk, with ICT capital having the most significant effect on reducing the variance of energy use. This supports the hypothesis that states that ICT capital and services value added decrease the variability in energy demand.

We believe that any increase in non-ICT capital with all other inputs held fixed must lead to a reduction in the level of energy demand risk, if the two variables are found to be substituting for one another. However, a complementary pattern between energy and non-ICT capital is found in this study, indicating the possibility of non-ICT capital to be a variance increasing input for energy. There are three input factors increasing the variability of energy: the demand for nonICT capital, material and labor. This supports the hypothesis that non-ICT capital and materials increase the variability of energy demand.

Looking at the marginal effects of industries' characteristics shows that mixed and domestic markets are relatively risk decreasing compared to the export oriented market. The greater export of energy intensive products could increase the industrial energy intensity. It is important to investigate the role of exports on energy intensity, as this can provide policy makers with the impact that energy has on existing and prospective export policies. This can assist the country in fulfilling its obligation in reducing its CO2 emission intensity (Zheng et al., 2011). Medium and low scale investments in $R \& D$ are risk increasing when compared to the high level of $R \& D$ investment. Industries that invest more in R\&D tend to adopt energy efficiency programs and tools. Medium and small size industries are risk decreasing compared to the larger size industries. New technologies, especially micro-electronics, allow small industries an inexpensive means to control an entire production process (Becchetti et al., 2003).

Industries with higher labor productivity and capital intensity decrease the energy demand variability, leading to an increase in the stability of energy use in the production process. Industries with more intensive capital investment are faster in their adjustment towards the adoption of energy efficiency programs (Fan et al., 2007). Limited access to capital may prevent energy efficiency measures from being implemented. Technologies that are energy efficient are often more expensive to purchase than alternative technologies. Furthermore, obtaining 
additional capital in order to invest in the energy efficient technology may be problematic. Apart from low liquidity, limited access to capital may also be due to the problem of credit accessibility. High skilled and medium skilled labors are risk decreasing factors compared to low skilled labor industries. The former can adapt new technologies which helps to efficiently use energy in production (Welsch and Ochsen, 2005). In the period after the first oil shock, the industry's energy demand was more stable than the period before the oil shock. The two oil price hikes forced many industries into saving by promoting conservation measures, switching to other fuels, and raising overall energy efficiency (Tsunoda et al., 2000).

\subsection{Technical Efficiency}

The technical efficiency component is also added to the risk model. As explained by Kumbhakar and Tveterås (2003), adding technical efficiency effects into the risk model will prevent the estimation from being misleading, as the allocation of inputs in the production process is affected by production risk and the presence of technical inefficiency. The mean values of technical efficiency estimates obtained from equation (18) are reported in Appendix Table C.4. Technical efficiency estimates by year, sector, and industries' characteristics are reported in Appendix Tables C.6, C.7, and C.8, respectively.

The overall technical efficiency is $24.4 \%$ with a small standard deviation of (0.259), indicating that industries in general are not efficient in their use of energy. The technical efficiency is slightly increasing over time except during the periods of the two oil shocks. However, a large variation across sectors is observed. A positive relationship is observed between technical efficiency and industries' level of technology (see Figure 2). High-tech industries are most efficient in energy use than low-tech and mid-tech industries.

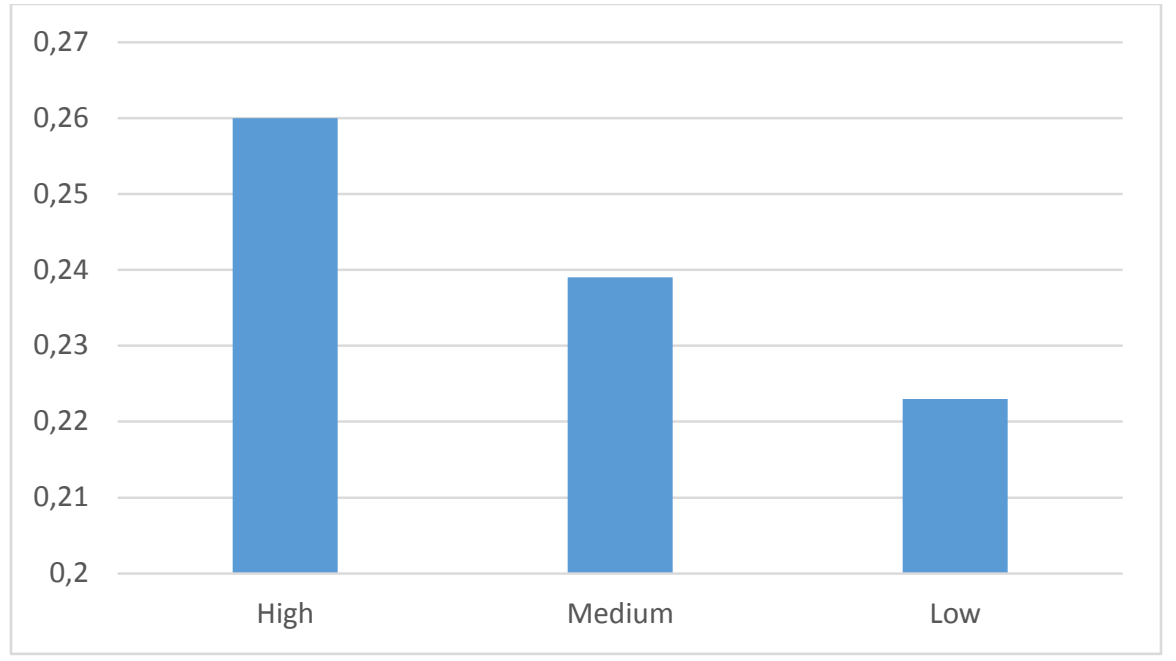

Figure 2. Technical Efficiency Based on Industries’ Technology Level

It is obvious that the available technological advancement in the high-tech industries allows for more efficiency and resource management, while for the low tech and mid tech industries these resources and technological advancement may be limited in a way that hinders these industries 
from using energy in an efficient manner. A positive relationship is also observed between technical efficiency and the scale of R\&D investment. Industries with a larger scale of R\&D tend to use energy more efficiently due to their access to advanced technologies and innovations (see Figure 3).

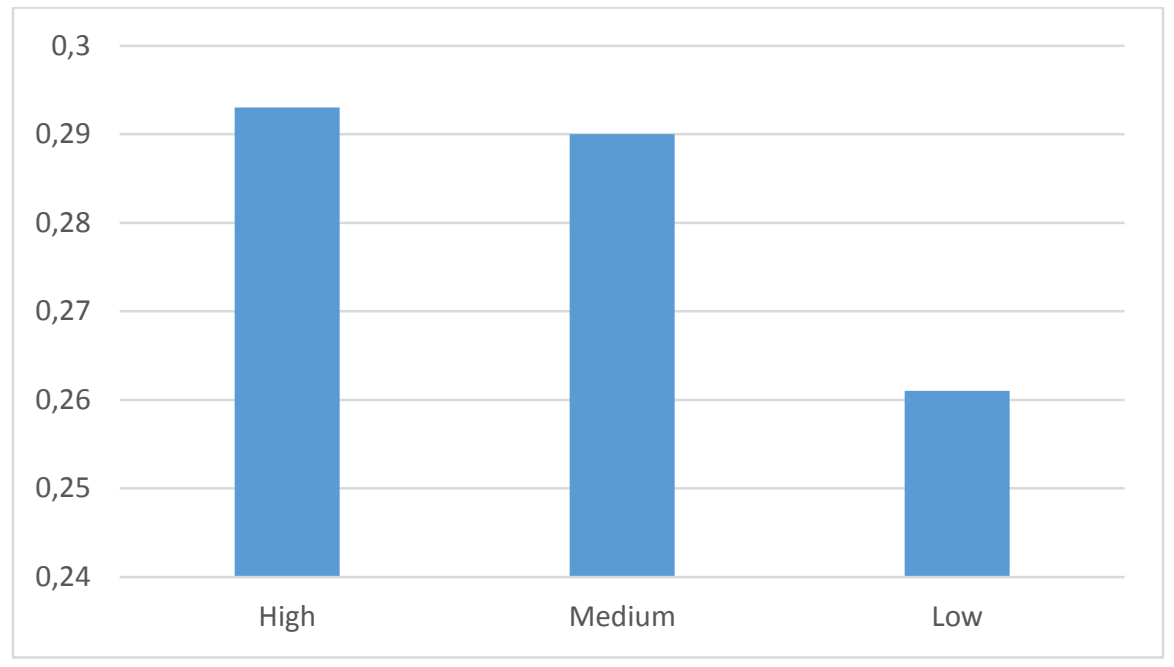

Figure 3. Technical Efficiency Based on Industries’ Scale of R\&D Investment

There is a negative relationship between technical efficiency and industry size. Smaller industries operate with a technically optimal size of energy inputs. There is low potential in the large and medium size industries to save energy (see Figure 4). Industries classified by mixed oriented (international and domestic) markets are comparatively more energy efficient than solely export oriented and domestic market oriented industries (see Figure 5). The mixed oriented industries are involved in the international market as well as domestic market. They are subjected to regulations imposed both in the international and domestic markets.

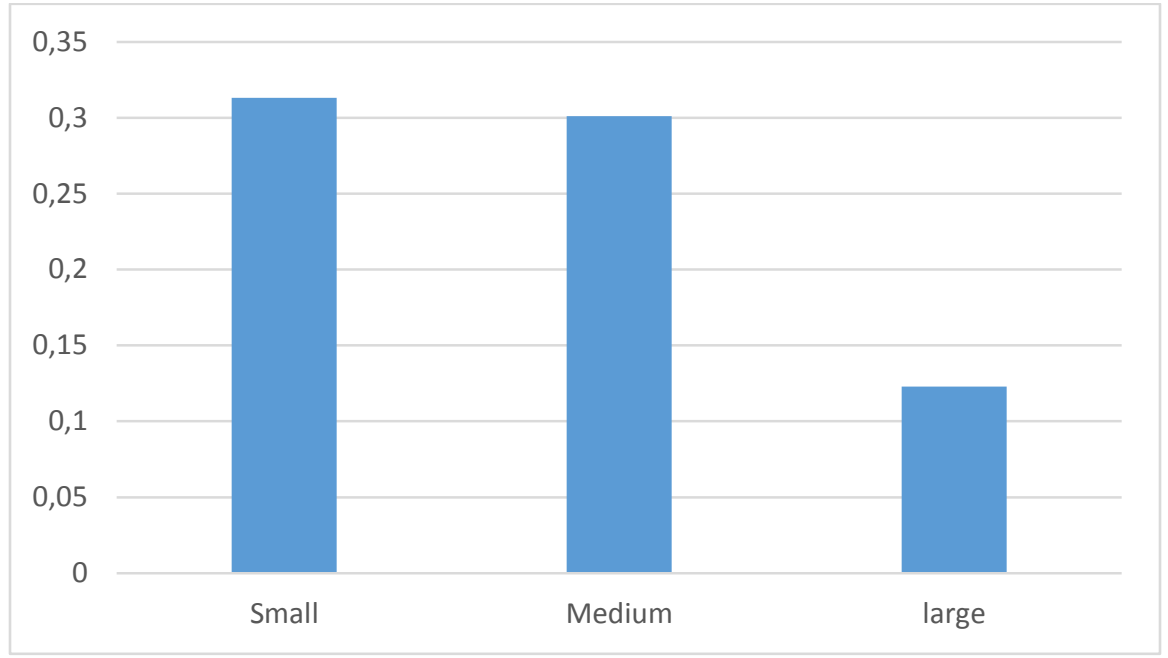

Figure 4. Technical Efficiency Based on Industries’ Size 


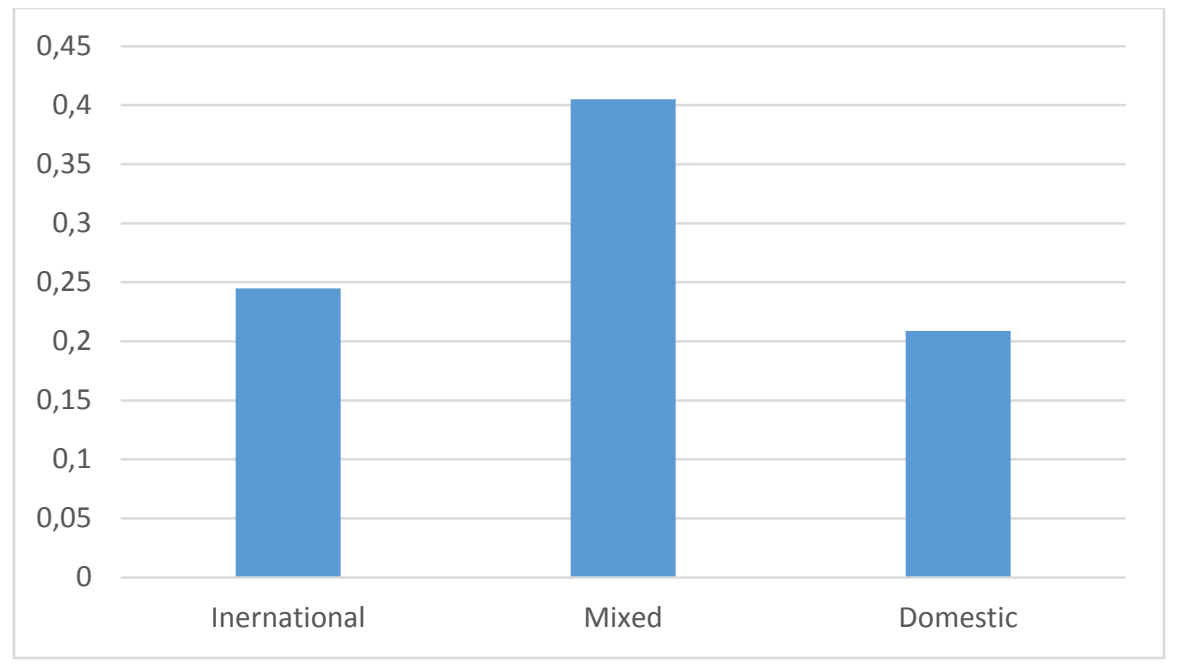

Figure 5. Technical Efficiency Based on Industries’ Export Orientation

\section{Concluding Remarks}

\subsection{Implications for Industry and Policy Makers}

It is difficult to say to what extent the risk properties of inputs have affected the industry's choice of the level of energy use in production. This depends on the risk preference structure of the producers and decision makers in the South Korean industrial sector. Due to lack of information, this study has not been able to measure this. Throughout the data period in this study, the South Korean industries have increased their scale of production. This has served to increase both the mean of energy demand and its related risks.

There are several possible explanations for such development of the mean and risk in energy demand based on the assumption that the producers and policy makers in the South Korean industrial sector are optimizing agents. One explanation is that the producers and policy makers in the South Korean industrial sector are risk neutral, in which case they are only concerned about the mean energy use. A second explanation is that even if the producers and policy makers are risk averse, their risk preference structure is such that the increase in the mean energy use associated with the increase in the scale of production is sufficient to compensate for the increase in energy use risk. This will thus provide them with the highest level of gained utility. A last possible explanation is that the producers and policy makers in the South Korean industrial sector have limited knowledge about the structure of the production risk, resulting in little knowledge about the effects of altering input levels for the optimal level of energy use in production.

The finding of this study should be of interest to the industry sector decision makers. This study is the first of its kind to evaluate the structure of energy demand and its related risks in South Korean industrial sector. Furthermore, the data set used here is the most extensive one for productivity studies of the South Korean industrial sector, with respect to both the length of the time period and the number of industries studied.

For an individual producer and individual sector in the South Korean industries, it is difficult to estimate the effects of changing input levels on the use of energy based on the productivity and 
energy use history. This study provides information on the structure of production risk based on a sample of 950 industrial sector and time observations. This implies that our conclusions can be drawn with higher confidence than if one must rely on observations from an aggregate industry. However, some caution is expressed in the interpretation of the results due to the quality of the data.

There are a number of ways industries can reduce their energy consumption. Improvements in the industrial process (especially in heating) may lead to a reduction in energy waste and an increase in energy recovery. Material recycling and fuel inputs are also considered factors subject to energy efficiency improvement. Policy makers and stakeholders my take these efficiency opportunities into account in their decision making. According to out empirical results, increasing the level of ICT capital, high investment in R\&D and value added services will reduce the variability of energy demand and its related risk. This finding suggests that risk averse producers should invest more in ICT and digitalization technologies and also invest more in $R \& D$ in order to reduce the uncertainty related to their demand for energy. It also supports another finding of this study that ICT capital is a substitute for energy inputs in most of the sectors over time. Investment in ICT will require more high skilled labor, which this study has also shown reduces the risk of energy use in production.

For public research programs aimed at the industrial sector, an implication of the empirical results in this study is that one should be concerned about both the mean and risk properties in research on new technologies and in investigating possible alternative inputs for energy. The results suggest that technical progress has contributed more to increasing the mean energy demand than to reducing the level of risk. However, it is an open question as to what extent this development has been driven by the producers and the government sponsored research and development programs.

\subsection{Conclusions and Practical Recommendations}

This study showed evidence that the introduction of risk has implications for factor use efficiency analysis. A risk averse producer will be concerned about both the mean input of energy and its variance when considering alternative input factors in the production process. This mean-variance tradeoff is represented by the producer's utility function.

It is believed that the results from this study, by using different model specifications for the production and energy requirement functions, will be useful for future empirical studies in this field of research. The empirical results considering the flexible energy requirement function have made it possible to evaluate how well energy conservation can be achieved in each of the Korean industries and to suggest guidelines concerning policy formulation and evaluations to further enhance the industry level energy use efficiency.

Energy prices and environmental problems are a major constraint on the development in different industries. Maximizing energy efficiency should be consistent with the public industrial development strategies. However, it is not always clear which choice will be made between pursuing greater intensive developments or less intensive development strategies. This study will help to shed light on how differently a certain policy affects each industry's performance and factor use. 


\subsection{Recommendations for Further Research}

Based on the findings of this study, it is believed that this quantitative study increases the reader's knowledge about the structure of the stochastic production technology in general and the energy demand structure of the South Korean industrial sector. In addition, this study has contributed to the discussion of model specification and estimator choice for empirical modeling of energy demand. In the course of the research work, several interesting paths were not entirely investigated, as the scope of the analysis would otherwise be too wide and perhaps less accurate.

In future research on energy demand and related risks within the Just and Pope framework, other parameterizations of the mean function, such as the generalized Leontief, should be examined. The focus should also be on flexibility, global properties and the effect on variance function estimates. A translog function seems to have a limited consistency region, as the estimated elasticities take extreme values as one moves away from the mean observation. If a functional form is not reliable at data points far from the mean, then this may also have consequences for variance function estimates. It should then be examined in future research what affects outlier observations may have on variance function estimates. In estimating the Korean industry-wide level of energy demand, one might employ a model of a dynamic energy requirement frontier accounting for risk. Such a model allows each industry to choose its own individual risk behavior parameters to catch up with their industry-wide global energy use requirement function and to formulate their production risk structure. 


\section{REFERENCES}

Abdelaziz, E.A., Saidur, R., Mekhilef, S., 2011. A review on energy saving strategies in industrial sector. Renewable \& Sustainable Energy Reviews 15, 150-168.

Aigner, D.J., Lovell, C.A.K., Schmidt, P., 1977. Formulation and estimation of stochastic production function models. Journal of Econometrics 6, 21-37.

Allan, G., Hanley, N., McGregor, P., Swales, K., Turner, K., 2007. The impact of increased efficiency in the industrial use of energy: A computable general equilibrium analysis for the United Kingdom. Energy Economics 29, 779-798.

Appelbaum, E., Ullah, A., 1997. Estimation of moments and production decisions under uncertainty. Review of Economics and Statistics 79, 631-637.

Arrow, K.J., 1971. Essays in the theory of risk bearing. Markham Press, Chicago.

Asche, F., Tveteras, R., 1999. Modeling production risk with a two-step procedure. Journal of Agricultural and Resource Economics 24, 424-439.

Battese, G.E., Heshmati, A., Hjalmarsson, L., 2000. Efficiency of labour use in the Swedish banking industry: a stochastic frontier approach. Empirical Economics 25, 623-640.

Becchetti, L., Bedoya, D., Paganetto, L., 2003. ICT Investment, Productivity and Efficiency: Evidence at Firm Level Using a Stochastic Frontier Approach. Journal of Productivity Analysis 20, 143-167.

Berndt, E.R., Wood, D.O., 1975. Technology, prices, and the derived demand for energy. The Review of Economics and Statistics 57, 259-268.

Binswanger, H.P., 1980. Attitudes toward risk: Experimental measurement in rural India. American Journal of Agricultural Economics 62, 395-407.

Caudill, S.B., Ford, J.M., Gropper, D.M., 1995. Frontier estimation and firm-specific inefficiency measures in the presence of heteroscedasticity. Journal of Business \& Economic Statistics 13, 105-111.

Cho, W.G., Nam, K., Pagan, J.A., 2004. Economic growth and interfactor/interfuel substitution in Korea. Energy Economics 26, 31-50.

Christensen, L.R., Jorgenson, D.W., Lau, L.J., 1973. Transcendental logarithmic production frontiers. The Review of Economics and Statistics 55, 28-45.

Coppejans, M., Gilleskie, D., Sieg, H., Strumpf, K., 2007. Consumer demand under price uncertainty: Empirical evidence from the market for cigarettes. Review of Economics and Statistics 89, 510-521.

Coyle, B.T., 1999. Risk aversion and yield uncertainty in duality models of production: A meanvariance approach. American Journal of Agricultural Economics 81, 553-567.

Diewert, W.E., 1974. Functional forms for revenue and factor requirements functions. International Economic Review 15, 119.

EIA, 2011. International Energy Outlook. U.S. Energy Information Administration.

EPA, 2007. Energy Trends in Selected Manufacturing Sectors: Opportunities and Challenges for Environmentally Preferable Energy Outcomes. Enviromental Protection Agency. 
Fan, Y., Liao, H., Wei, Y.-M., 2007. Can market oriented economic reforms contribute to energy efficiency improvement? Evidence from China. Energy Policy 35, 2287-2295.

Friedemann, M., Staake, T., Weiss, M., 2010. Ict for Green: How Computers Can help us to conserve Energy, Proceedings of the 1st International Conference on Energy-Efficient Computing and Networking, Passau, Germany.

Fufa, B., Hassan, R.M., 2003. Stochastic maize production technology and production risk analysis in dadar district, east ethiopia. Agrekon 42, 116-128.

Fukao, K., Miyagawa, T., Pyo, H.K., 2009. Estimates of multifactor productivity, ICT contributions and resource reallocation effects in japan and korea, RIETI Discussion Paper Series 09-E-021.

Gallant, A.R., 2008. Nonlinear Statistical Models. John Wiley \& Sons, Inc.

Greene, W.H., 2008. Econometric Analysis, 7th ed. Prentice Hall.

Griffin, J.M., Gregory, P.R., 1976. An intercountry translog model of energy substitution responses. The American Economic Review 66, 845-857.

Griffiths, W.E., Anderson, J.R., 1982. Using time-series and cross-section data to estimate a production function with positive and negative marginal risks. Journal of the American Statistical Association 77, 529-536.

Harvey, A.C., 1976. Estimating regression-models with multiplicative heteroscedasticity. Econometrica 44, 461-465.

Heshmati, A., 2001. Labour demand and efficiency in Swedish savings banks. Applied Financial Economics 11, 423-433.

Heshmati, A., 2003. Productivity growth, efficiency and outsourcing in manufacturing and service industries. Journal of Economic Surveys 17, 79-112.

Heshmati, A., 2014. Demand, customer base-line and demand response in the electricity market: A survey. Journal of Economic Surveys, in press.

Hicks, J.R., 1961. Marshall's third rule: A further comment. Oxford Economic Papers 13, 262265.

Hurd, B.H., 1994. Yield response and production risk - an analysis of integrated pestmanagement in cotton. Journal of Agricultural and Resource Economics 19, 313-326.

IEA, 2011. Climate \& Electricity Annual: Data and Analysis. International Energy Agency.

Just, R.E., Pope, R.D., 1978. Stochastic specification of production functions and economic implications. Journal of Econometrics 7, 67-86.

Kamerschen, D.R., Porter, D.V., 2004. The demand for residential, industrial and total electricity, 1973-1998. Energy Economics 26, 87-100.

Koundouri, P., Nauges, C., 2005. On production function estimation with selectivity and risk considerations. Journal of Agricultural and Resource Economics 30(3), 597-608.

Koundouri, P., Nauges, C., Tzouvelekas, V., 2006. Technology Adoption under production uncertainty: Theory and application to irrigation technology. American Journal of Agricultural Economics 88, 657-670. 
Kumbhakar, S.C., 1997. Efficiency estimation with heteroscedasticity in a panel data model. Applied Economics 29, 379-386.

Kumbhakar, S.C., 2002a. Risk preference and productivity measurement under output price uncertainty. Empirical Economics 27, 461-472.

Kumbhakar, S.C., 2002b. Risk preferences and technology: A joint analysis. Marine Resource Economics 17, 77-89.

Kumbhakar, S.C., Hjalmarsson, L., Heshmati, A., 2002. How fast do banks adjust? A dynamic model of labour-use with an application to Swedish banks. Journal of Productivity Analysis 18, 79-102.

Kumbhakar, S.C., Tsionas, E.G., 2010. Estimation of production risk and risk preference function: a nonparametric approach. Annals of Operations Research 176, 369-378.

Kumbhakar, S.C., Tveterås, R., 2003. Risk preferences, production risk and firm heterogeneity. Scandinavian Journal of Economics 105, 275-293.

Lee, W.N., Kim, H.J., Park, J.B., Roh, J.H., Cho, K.S., 2012. An economic evaluation of the energy efficiency programs in Korea. Journal of International Council on Electrical Engineering 2, 219-224.

Liu, Y., 2009. Exploring the relationship between urbanization and energy consumption in China using ARDL (autoregressive distributed lag) and FDM (factor decomposition model). Energy 34, 1846-1854.

Lovell, C.A.K., Schmidt, P., 1987. A Comparison of Alternative Approaches to the Measurement of Productive Efficiency, in: Dogramaci, A., Färe, R. (Eds.), Applications of Modern Production Theory: Efficiency and Productivity. Springer Netherlands, pp. 3-32.

Moss, C.B., Erickson, K.W., Ball, V.E., Mishra, A.K., 2003. A Translog Cost Function Analysis of U.S. Agriculture: A Dynamic Specification. American Agricultural Economics Association (New Name 2008: Agricultural and Applied Economics Association).

Mukherjee, K., 2008. Energy use efficiency in U.S. manufacturing: A nonparametric analysis. Energy Economics 30, 76-96.

O'Mahony, M., Timmer, M.P., 2009. Output, input and productivity measures at the industry level: The EU KLEMS database. The Economic Journal 119, F374-F403.

Pratt, J.W., 1964. Risk-aversion in the small and in the large. Econometrica 32, 122-136.

Robison, L., P., B., 1987. The competitive firm's response to risk. MacMillan Publishing Company.

Sandmo, A., 1971. On the theory of the competitive firm under price uncertainty. The American Economic Review 61, 65-73.

Shephard, R.W., 1953. Cost and production functions. Princeton University Press, Princeton: USA.

Soytas, U., Sari, R., 2009. Energy consumption, economic growth, and carbon emissions: Challenges faced by an EU candidate member. Ecological Economics 68, 1667-1675. 
Stern, D.I., 2011. The role of energy in economic growth. Annals of the New York Academy of Sciences 1219, 26-51.

Tsunoda, J., Inui, T., Takeuchi, A., 2000. Environmental conservation by Japan’s electric power industry: An example of the Electric Power Development Company, in: al(Eds.), W.C.e. (Ed.), Protecting the global environment; initiatives by Japanese business Washington, DC: World Bank, pp. 77-79.

Tveterås, R., 1997. Econometric Modelling of Production Technology Under Risk: The Case of Norwegian Salmon Aquaculture Industry. Norwegian School of Economics and Business Administration, Bergen, Norway.

Tveterås, R., 1999. Production risk and productivity growth: Some findings for Norwegian Salmon aquaculture. Journal of Productivity Analysis 12, 161-179.

Tveterås, R., 2000. Flexible panel data models for risky production technologies with an application to Salomon aquaculture. Journal of Econometric Reviews 19, 367-389.

Tveteras, R., Flaten, O., Lien, G., 2011. Production risk in multi-output industries: estimates from Norwegian dairy farms. Applied Economics 43, 4403-4414.

Tveterås, R., Heshmati, A., 2002. Patterns of productivity growth in the norwegian salmon farming industry. International Review of Economics and Business 2, 367-393.

Urga, G., Walters, C., 2003. Dynamic translog and linear logit models: a factor demand analysis of interfuel substitution in US industrial energy demand. Energy Economics 25, 1-21.

Wansbeek, T.J., Kapteyn, A.J., 1989. Estimation of the error-components model with incomplete panels. Journal of Econometrics 41, 341-361.

Welsch, H., Ochsen, C., 2005. The determinants of aggregate energy use in West Germany: factor substitution, technological change, and trade. Energy Economics 27, 93-111.

Zheng, Y., Qi, J., Chen, X., 2011. The effect of increasing exports on industrial energy intensity in China. Energy Policy 39, 2688-2698. 
Appendix A: Just and Pope Propositions for Production Risk

Proposition 1: The expected value of production is always positive, i.e. $E(y)>0$.

Proposition 2: The expected value of the marginal product is always positive, i.e. $\frac{\partial E(y)}{\partial x_{k}}>0$.

Proposition 3: There is a diminishing marginal product expectation, i.e. $\frac{\partial^{2} E(y)}{\partial x_{k}^{2}}<0$.

Proposition 4: A change in the variance for random components in production should not necessarily imply a change in expected output when all production factors are held fixed, i.e. $\frac{\partial E(y)}{\partial \operatorname{Var}(\varepsilon)}=0$ is possible.

Proposition 5: Increasing, decreasing, or constant marginal risk should all be possible, i.e. $\frac{\partial \operatorname{Var}(y)}{\partial x_{k}}<=>$ possibile. Proposition 5 is considered of particular interest in this study. It states that the specification of the production function should not restrict the effects of the change in the level of an input on the variance of output a priori.

Proposition 6: A change in risk should not necessarily lead to a change in factors used for risk neutral producers (profit maximizers), i.e. $\frac{\partial x_{k}^{*}}{\partial \operatorname{Var}(\varepsilon)}=0$ is possible. Where $x^{*}$ is the optimal level of input $x$.

Proposition 7: The change in the variance of marginal product with respect to a factor change should not be constrained in sign a priori without regard to the nature of the input, i.e. $\frac{\partial \operatorname{Var}\left(\partial y / \partial x_{k}\right)}{\partial x_{j}}<=>$ are all possible.

Proposition 8: Constant stochastic returns to scale should be possible, i.e. $f(\alpha x)=\alpha f(x)$ possible for scalar $\alpha$. 


\section{Appendix B: Data Sources and Construction of the Variables}

The data used in this study (See Table B.1) are obtained from secondary data sources, mainly the harmonized EU KLEMS growth and productivity accounts database. The input measures include various categories of capital, labor, energy use, materials, ICT capital, and services inputs. Total hours worked is used for the labor input. The materials and energy use inputs are computed from the proportion of each of these inputs from the national accounts. Energy use is defined as the aggregate of energy mining, oil refining, and electricity and gas products ${ }^{1}$.

In addition to the measures mentioned above, other variables are included for export/importoriented industries, industry size, $\mathrm{R} \& \mathrm{D}$ intensity, and labor skills for the 30 sampled sectors (see Table B.2).

\section{Appendix Table B.1}

Definition of variables used

\begin{tabular}{lll}
\hline Variable & Formula & Source \\
\hline Industry Code & & \\
Year & & \\
IFPV & $\begin{array}{l}\text { Price Index of Gross Output (Index, } \\
\text { 1995=100 for Korea) }\end{array}$ & $\begin{array}{l}\text { EU KLEMS Growth and Productivity Database } \\
\text { for Korea }\end{array}$ \\
IFPE & Price Index of Energy & $=$ \\
PVV & PVV = Gross Output In Current & $=$ \\
& Prices & \\
PKK & Real Non ICT Capital Services (In & The Real Capital Stock is taken form the KIP \\
& 1995 Prices for Korea) & Database for Korea. The physical share of non- \\
& & $\begin{array}{l}\text { ICT Capital is calculated after subtracting the real } \\
\text { share of ICT Capital. }\end{array}$ \\
PICT & Real ICT Capital Services & The share is taken from the KLEMS database, \\
& multiplied by the Real Capital Stock \\
PLL & Total Hours Worked By Employees & $=$ \\
PEE & Cost of Energy Input (Million KW) & $=$ \\
PMM & Cost of Materials Input (Million & $=$ \\
& Dollars) & \\
\hline Constructed Variables & \\
\hline PFPK & (IFPK/100)*(RIR+CDR)*(1-CITR) & Non-ICT Capital Rental Price Index \\
PFPE & IFPE/100 & Energy Price Index \\
PFPV & IFPV/100 & Gross Output Price Index \\
QK & PKK/PFPK & Quantity of Non-ICT Capital \\
QL & PLL/PFPL & Quantity of Labor Input \\
QE & PEE/PFPE & Quantity of Energy Input \\
QM & PMM/PFPM & Quantity of Materials Input \\
QICT & PICT/PFPICT & Quantity of ICT Capital Input \\
QGO & PVV/PFPV &
\end{tabular}

\footnotetext{
${ }^{1}$ For details about the KLEMS growth accounting database, see O'Mahony, M., Timmer, M.P., 2009. Output, input and productivity measures at the industry level: The EU KLEMS database. The Economic Journal 119, F374-F403.
} 


\section{Appendix Table B. 2}

Industry Sectors Classification ${ }^{*}$

\begin{tabular}{|c|c|c|c|c|}
\hline ID & Description & $\begin{array}{l}\text { Technology } \\
\text { Level }\end{array}$ & $\begin{array}{l}\text { Export Market } \\
\text { Orientation }\end{array}$ & $\begin{array}{l}\mathrm{R} \& \mathrm{D} \\
\text { Intensity }\end{array}$ \\
\hline 1 & Agriculture, Hunting, Forestry and Fishing & $\mathrm{L}$ & $\mathrm{L}$ & $\mathrm{M}$ \\
\hline 2 & Mining and Quarrying & $\mathrm{L}$ & $\mathrm{L}$ & $\mathrm{L}$ \\
\hline 3 & Food, Beverages and Tobacco & $\mathrm{L}$ & M & M \\
\hline 4 & Textiles, Leather and Footwear & $\mathrm{L}$ & I & $\mathrm{M}$ \\
\hline 5 & Wood and Cork & $\mathrm{L}$ & $\mathrm{L}$ & $\mathrm{L}$ \\
\hline 6 & Pulp, Paper, Printing and Publishing & $\mathrm{L}$ & M & $\mathrm{H}$ \\
\hline 7 & Coke, Refined Petroleum and Nuclear Fuel & $\mathrm{H}$ & $\mathrm{L}$ & $\mathrm{H}$ \\
\hline 8 & Chemicals and Chemical Products & $\mathrm{H}$ & I & $\mathrm{M}$ \\
\hline 9 & Rubber and Plastics & $\mathrm{H}$ & I & M \\
\hline 10 & Other Non-Metallic Mineral & M & M & M \\
\hline 11 & Basic Metals and Fabricated Metal & M & M & $\mathrm{L}$ \\
\hline 12 & Machinery, NEC & $\mathrm{H}$ & I & $\mathrm{H}$ \\
\hline 13 & Electrical and Optical Equipment & $\mathrm{H}$ & I & $\mathrm{H}$ \\
\hline 14 & Transport Equipment & $\mathrm{H}$ & I & $\mathrm{M}$ \\
\hline 15 & Manufacturing NEC; Recycling & $\mathrm{H}$ & I & M \\
\hline 16 & Electricity, Gas and Water Supply & $\mathrm{M}$ & $\mathrm{L}$ & $\mathrm{H}$ \\
\hline 17 & Construction & $\mathrm{H}$ & I & $\mathrm{H}$ \\
\hline 18 & $\begin{array}{l}\text { Sale, Maintenance and Repair of Motor Vehicles } \\
\text { and Motorcycles; Retail Sale of Fuel }\end{array}$ & $\mathrm{L}$ & $\mathrm{L}$ & $\mathrm{L}$ \\
\hline 19 & $\begin{array}{l}\text { Wholesale Trade and Commission Trade, Except } \\
\text { of Motor Vehicles and Motorcycles }\end{array}$ & $\mathrm{L}$ & $\mathrm{L}$ & $\mathrm{L}$ \\
\hline 20 & $\begin{array}{l}\text { Retail Trade, Except of Motor Vehicles and } \\
\text { Motorcycles; Repair of Household Goods }\end{array}$ & $\mathrm{L}$ & $\mathrm{L}$ & $\mathrm{L}$ \\
\hline 21 & Hotels and Restaurants & $\mathrm{L}$ & $\mathrm{L}$ & $\mathrm{L}$ \\
\hline 22 & Transport and Storage & $\mathrm{M}$ & $\mathrm{L}$ & $\mathrm{L}$ \\
\hline 23 & Post and Telecommunications & $\mathrm{H}$ & I & $\mathrm{H}$ \\
\hline 24 & Financial Intermediation & M & $\mathrm{L}$ & $\mathrm{H}$ \\
\hline 25 & Real Estate Activities & $\mathrm{L}$ & $\mathrm{L}$ & $\mathrm{L}$ \\
\hline 26 & Renting of M\&Eq and Other Business Activities & $\mathrm{L}$ & $\mathrm{L}$ & $\mathrm{L}$ \\
\hline 27 & $\begin{array}{l}\text { Public Admin and Defense; Compulsory Social } \\
\text { Security }\end{array}$ & $\mathrm{L}$ & $\mathrm{L}$ & $\mathrm{L}$ \\
\hline 28 & Education & $\mathrm{L}$ & $\mathrm{L}$ & $\mathrm{H}$ \\
\hline 29 & Health and Social Work & $\mathrm{H}$ & $\mathrm{L}$ & $\mathrm{L}$ \\
\hline 30 & Other Community, Social And Personal Services & $\mathrm{L}$ & $\mathrm{L}$ & $\mathrm{L}$ \\
\hline
\end{tabular}

*The letters H, M, and L refer to High, Medium, and Low levels, respectively. 